\title{
Sexually transmitted diseases and the mobility explosion
}

\author{
R. D. Catterall \\ F.R.C.P.E.
}

James Pringle House, The Middlesex Hospital, London WI

\begin{abstract}
Summary
The very great increase in the tourist industry during the past 20 years is described. This has occurred at a time when there has been an unprecedented rise in the incidence of sexually transmitted diseases. Evidence is presented that there is a relationship between the number of tourists and other travellers and the prevalence of sexually transmitted diseases. Case histories from three different categories of tourist are described and the impact of tourism on the spread of disease is stressed. It is suggested that health authorities throughout the world should give further consideration to plans to meet the challenge of the mobility explosion.
\end{abstract}

DURING the past 20 years tourism has been one of the fastest growing areas of human activity. It has now become of major economic importance and without it the balance of payments of many countries would present serious difficulties. The sums of money involved are enormous and in 1972 the total expenditure on tourism throughout the world was over $£ 8$ billion. The number of tourists has increased at an accelerating rate and the figures available indicate that over 215 million people arrived at national frontiers in 1973 whilst tourist arrivals in the United Kingdom rose from 200,000 in 1946 to 8.4 million in 1973.

This enormous expansion in the mobility of large numbers of people has inevitably resulted in many problems. The growth of the so-called tourist industry has brought the man in the street into direct contact with the ever increasing number of holiday makers and others. To many this growth appears to be an exciting and desirable development of modern life, but to others there are grave dangers to the quality of life resulting from this new phenomenon.

TABLE 1. Tourists arriving at frontiers

\begin{tabular}{rcrrr}
\hline Year & Europe & $\begin{array}{c}\text { North } \\
\text { America }\end{array}$ & $\begin{array}{c}\text { Other } \\
\text { regions }\end{array}$ & \multicolumn{1}{c}{$\begin{array}{l}\text { World } \\
\text { total }\end{array}$} \\
\hline 1950 & $16,839,400$ & $6,179,650$ & $6,896,300$ & $92,569,000$ \\
1970 & $126,700,000$ & $27,000,000$ & $13,900,000$ & $168,000,000$ \\
1973 & $156,000,000$ & $44,000,000$ & $13,400,000$ & $215,000,000$ \\
\hline
\end{tabular}

For them the beautiful open spaces of Europe will soon be covered with airports, the air will be filledo with the noise of jumbo jets, the larger cities will be 3 . submerged by new hotels, the roads will be con-ir gested with tourist coaches and hired cars, he historic buildings will be cluttered with visitors, the beauty spots ruined by crowds and the streets of ouroo capitals overrun with souvenir shops, boutiques and $\infty$ strip clubs.

Many grave problems need to be considered and the phrase 'tourist pollution' has now become common currency.

At the same time that there has been this explosion $\frac{}{3}$ in tourism there has also been a very great increase $\frac{1}{\pi} \bar{\Phi}^{\circ}$ the incidence of the venereal and sexually transmitted diseases. Although accurate figures are difficult obtain from most countries, the World Heal Organization has issued a statement indicating thăt these diseases are completely out of control in most countries and have reached epidemic proportions in some areas of the world. It is estimated that in $1973 \AA$

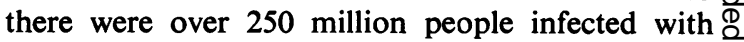
gonorrhoea and about 50 million people infected $\overrightarrow{\vec{A}}$ with syphilis throughout the world. The incidence $\frac{9}{3}$ of the other sexually transmitted diseases is unknown.

In Britain the trends in incidence of the majorityo of the diseases has been similar but the rates of infection per hundred thousand of the population 3 have been lower than in most comparable industrial 0 countries. Nevertheless, the number of new patients seen at the 220 clinics specializing in sexually trans- $\delta$ mitted diseases in the United Kingdom has risen at 3 an accelerating rate and in 1973 well over 300,000 을 new patients presented themselves for consultation $D$ with the doctors. The commonest disease diagnosed in Britain is non-specific genital infection, of which the cause is still completely unknown. Gonorrhoea o has also shown a steady increase in incidence and is $N$ now a very common disease, widely diffused through- N out the population. Only with syphilis does there 0 appear to be a measure of control in Britain, but this

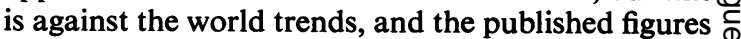
for 1973 show a sharp increase in England compared $\stackrel{\oplus}{\rightarrow}$ to 1972. The number of cases of the majority of the 0 other 13 or 14 sexually transmissible diseases is also 
rising and they are now the commonest notifiable infectious diseases in the world.

Not only are the number of patients continuing to grow but the number of diseases which have been shown to be spread by sexual contact is also expanding. For example, recent work has resulted in the accumulation of evidence indicating that the commonest mode of spread of hepatitis B is by sexual contact and studies are now being carried out to try to determine the exact route of spread of the responsible agent.

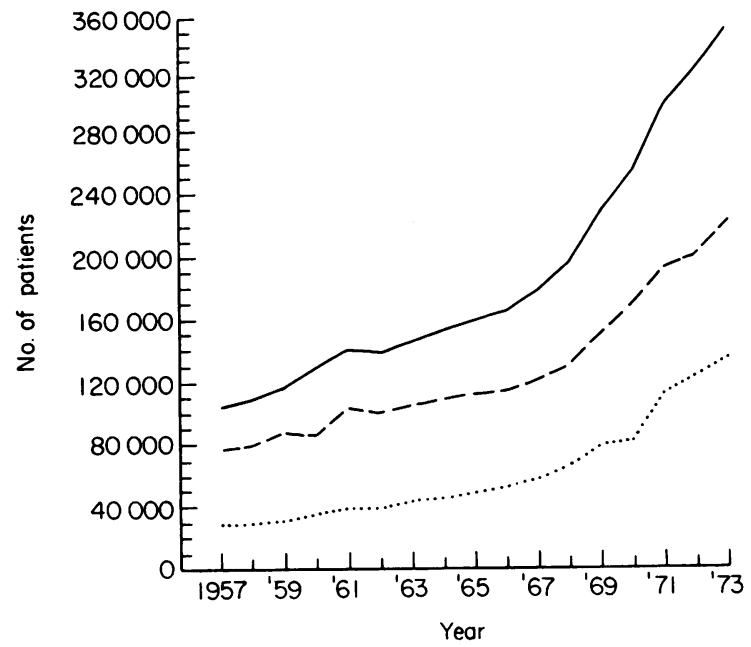

FIG. 1. New patients attending clinics in England and Wales. ——, total; _ _ - men; ......, women.

This great rise in the prevalence of sexually transmitted disease is a paradox of modern medicine. Throughout this century there has been a steady decline in the incidence of the majority of infectious diseases, such as tuberculosis, diphtheria, scarlet fever, enteric fever, and more recently poliomyelitis, until many of these conditions have become uncommon and have ceased to be a threat to the health and lives of contemporary mankind. On the other hand, the diseases of sex are increasing to a point where they are widely diffused throughout all educational and economic levels of society and control measures are obviously ineffective in the majority of countries.

Is there any relationship between the explosive expansion of modern travel and tourism and the continuing increase in the incidence of the sexually transmitted diseases? Obviously there are many factors, both medical and social, responsible for the present disappointing situation. They include changes in sexual behaviour in recent years, the emergence of strains of organisms relatively insensitive to antibiotics, the widespread use of con-

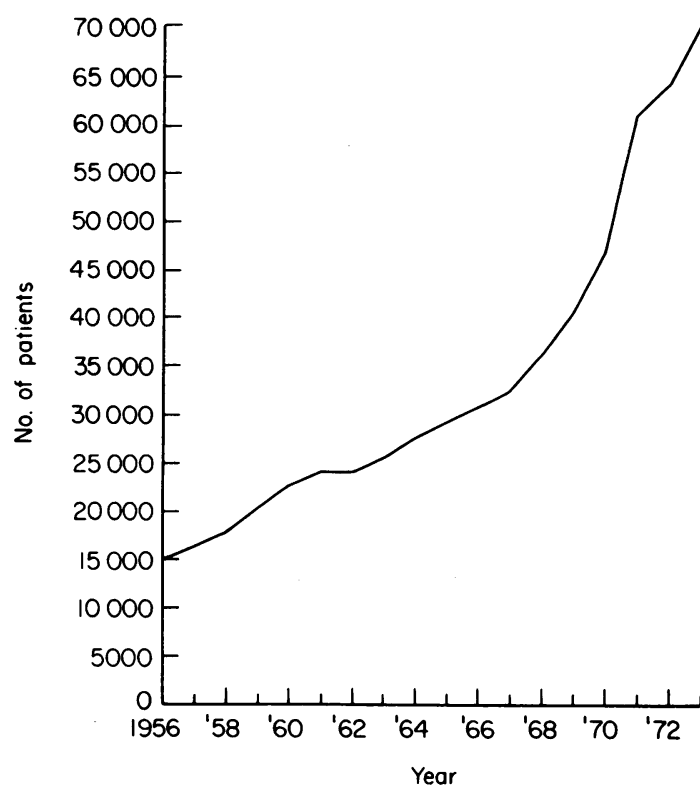

FIG. 2. Incidence of non-specific urethritis in England and Wales.

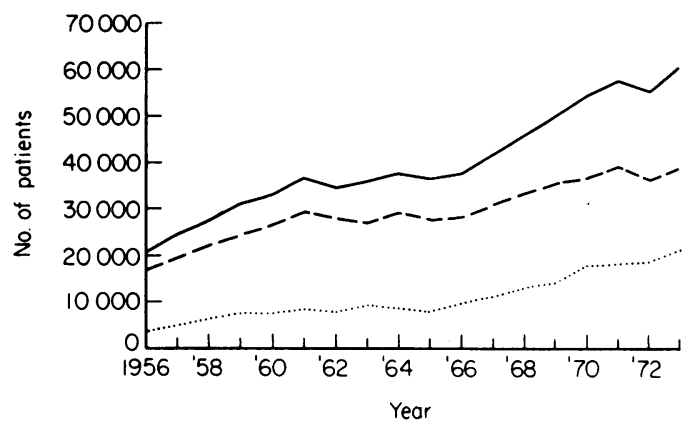

FIG. 3. Incidence of gonorrhoea in England and Wales. , Total; - - - men; ......, women.

traceptive pills, more overt and frequent homosexual activity and above all ignorance. Ignorance about sex and its disease is not limited to the public but is regrettably widespread in the medical profession throughout the world. Control failure is frequently physician failure, especially in recognition, diagnosis, treatment, follow-up and contact tracing.

Evidence is becoming available to show a definite relationship between the number of tourists, the extent of their travels and the prevalence of sexually transmitted diseases. Accurate figures are difficult to obtain but Caletti (1974) has produced figures to show that an increasing number of infections, with both gonorrhoea and syphilis, diagnosed among 


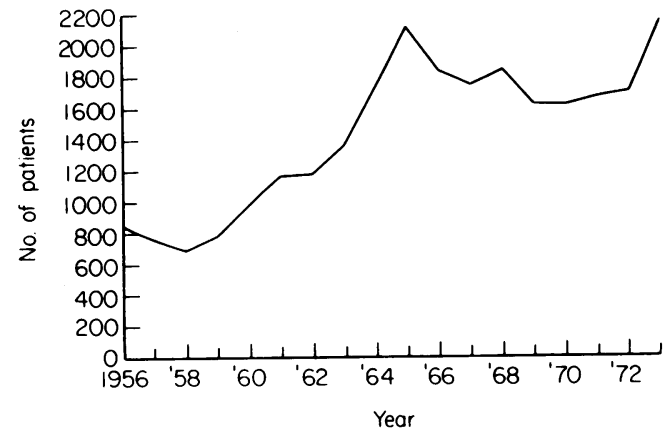

FIG. 4. Incidence of early infectious syphilis in England and Wales.

residents in Venice, were contracted from tourists and visitors to the city. Siboulet (1973) has reported an increase in the number of patients seen in his practice in Paris, who were foreigners infected during their travels in Europe, and Guthe (1974) has drawn the attention of the Council of Europe to the magnitude of the problem and the dangers involved if tourism continues to expand and adequate measures are not taken to provide high quality clinical services throughout Europe.

TABLE 2. Cases of S.T.D. in England 1972 (population 46,297,500)

\begin{tabular}{lr}
\hline Disease & $\begin{array}{c}\text { No. } \\
\text { cases }\end{array}$ \\
\hline Non-specific genital infection & 76,916 \\
Gonorrhoea & 53,439 \\
Candidosis & 29,844 \\
Trichomoniasis & 19,100 \\
Genital warts & 15,820 \\
Genital herpes & 4,380 \\
Pediculosis pubis & 4.099 \\
Syphilis & 2,965 \\
Scabies & 2,771 \\
Other treponemal diseases & 853 \\
Molluscum contagiosum & 634 \\
Lymphogranuloma venereum & 59 \\
Chancroid & 49 \\
Granuloma inguinale & 5 \\
\hline
\end{tabular}

In the past it has been shown that the incidence of sexually transmitted diseases is much higher among immigrants than in the indigenous population, especially among men. For example, Willcox (1966) showed that West Indian men were responsible for about $50 \%$ of all the cases of gonorrhoea in England and Wales and for about four out of ten cases of primary and secondary syphilis at the peak of immigration from the Caribbean early in the 1960s. Men of Asian origin also had a high rate of infection as did those of Mediterranean origin. However, as the immigrants have become more settled and integrated into the community the infection rates have fallen and a study carried out by the British Co-operative Clinical Group in 1968 indicated that these had fallen to nearly that of the indigenous population.

Similar trends have occurred in many European 7 countries where immigrants and guest workers have 흠 poured into the prosperous, expanding industrial cities. Well over six million of them live in poor sur- $\mathbb{\AA}$ roundings and inadequate housing, especially in France, and the incidence of sexually transmitted diseases has been very high among them.

Traditionally seamen and mariners have been a $\overrightarrow{\vec{\omega}}$ particularly high risk group (Schofield, 1965), but the increasing automation on modern ships, with the 8 consequent reduction in the size of crews and the 3 . enormous increase in the size of ships, has led to a ir considerable reduction in the problem of this group. In some ways their place has been taken by air pilots and air crews as a result of the massive growth of air travel and of air freight transport.

But it is to modern tourism that we must turn for 을 some of the most fascinating and intricate problems of modern medicine and public health. Just who is a tourist? In general terms a tourist is someone who $\varnothing$ travels away from home and, if this broad definition 3 is accepted, it is convenient to divide tourists into three categories. They are those travelling for plea sure, those travelling on business and those travelling to attend conferences. Each category has its ov special problems and motivations, just as each hà its own travel patterns, spending habits, entertainment preferences and sexual habits.

The largest section of the international market and the fastest growing group are those who travel for $\stackrel{\unrhd}{\unrhd}$ pleasure. This has resulted from the rising levels of $\overrightarrow{\vec{A}}$ incomes in Western Europe and North America as $\frac{0}{3}$ well as the longer periods of paid holidays. But teenagers and other young people at the age of maximal sexual activity, travel more than most other groups. Their ability to accept some of the 3 discomforts of life, to hitch-hike and sleep rough, $\dot{\sigma}$ together with the informality and sexual freedom of their mode of life, provides them with frequent $\delta$ opportunities for sexual activity often of a very casual and inconsequential nature. If they should be $ᄋ$ infected with a sexually transmitted disease they often $D$ do not have the money for a medical consultation in countries without a free National Health Service and there are difficult problems in tracing their 5 sexual contacts once an accurate diagnosis has been $\mathbb{O}$ made.

An example of these difficulties is illustrated by the case of a seventeen-year-old Yorkshire girl who set out with another girl friend to hitch-hike across $\underset{\mathbb{C}}{\mathbb{C}}$ Europe to Rome by way of the south of France. $\stackrel{?}{-}$ After several days they obtained a lift with two young $T$ French businessmen who were driving down to 
Aix-en-Provence and undertook to take them to that city. The atmosphere was gay and relaxed in the car and as they neared their destination the Frenchmen gallantly invited them both to dinner and to share their comfortable hotel bedrooms afterwards. No names or addresses were exchanged and the following day the girls obtained a lift in a lorry to Nice. During their stay on the Côte d'Azur they met an American pop group, who were wandering through Europe without any special time schedule. They became friendly with two members of the group and had sex with them on several occasions. A few days later they travelled to Florence and on the Ponte Vecchio met two blond Swedish boys, who agreed to travel to Rome with them. The Swedes assumed that sex was a normal part of the arrangement but after only 3 days in Rome the Yorkshire girl developed severe, recurrent lower abdominal pain and one of the Swedish boys complained that he had developed burning on micturition and a discharge. The girls were both frightened and used their reserve of money to travel back to England by train and boat. When they were examined at the Middlesex Hospital, the Yorkshire girl was found to have severe, bilateral gonococcal salpingitis and her companion to have trichomonal vaginitis and vulval and perianal warts. Attempts to warn the boys that they might be infected were fruitless as the only names that the girls knew were Jean-Louis, Albert, Hank, Bob, Bengt and Per. No family names, no addresses, no telephone numbers, resulting in total failure of any form of contact tracing.

Business travellers are totally different from tourists. There are fewer of them, they travel more often and spend more money, usually on an expense account. They are very important to the hotel and restaurant business and help to support the strip clubs and night clubs. In Zürich they account for $64 \%$ of hotel visitors and in the United Kingdom it is estimated that travelling salesmen spend one million nights per year in some type of commercial accommodation. They frequently get bored with hotels and seek entertainment and companionship in pubs and clubs in the towns they visit.

A very successful director of an important engineering company visited Warsaw to try to secure a large order, worth several million pounds, from the Polish government. Against fierce competition he succeeded in obtaining the order for his firm. That evening he and his friends went out to celebrate. After the usual drinks and a large dinner accompanied by liberal quantities of red wine, followed by brandy, they decided to move on to a night club. After several further drinks the director was approached by a night club hostess for whom he bought 2 bottles of Russian champagne. In the small hours of the morning he found himself in her flat having had some form of rather unsatisfactory sexual intercourse. He immediately returned to his hotel and woke up the following morning with a severe headache and feeling very ashamed of himself. That afternoon he flew back to Heathrow Airport, where his wife, who had learnt by telephone of his success with the export order, awaited him with the family Rover. She had put a bottle of champagne in the refrigerator to celebrate and after a pleasant and intimate dinner together they went to bed and had normal marital sexual intercourse.

Five weeks later he developed a painless ulcer on the penis and some lumps in the groin. Being an intelligent man he came straight to James Pringle House at the Middlesex Hospital, where he was found to have a classical primary chancre from which treponemes were demonstrated under the dark ground microscope. Once he had started his treatment the question of contact tracing was discussed with him. He was horrified at the prospect of having to tell his wife and said she would divorce him instantly. He only knew the first name of the night club hostess in Warsaw but he remembered the name of the club. A letter was sent to a colleague in Warsaw with the available information and the diagnosis in our patient and it was learnt later that the girl had been found, warned that she might have syphilis and should have a medical check-up. She was found to have secondary syphilis and given treatment. It took the patient over 2 weeks to find a way of persuading his wife to be? examined and she was found to have a developing primary chancre on the vulva. She was given treatment with excellent results and they are still living together in apparent harmony.

The increasing specialization in most fields of human activity and the enormous technical progress of the past 25 years has resulted in the modern proliferation of national and international conferences. In 1971 it was estimated that there were over 5,000 major international conferences attended by over 3 million delegates and bringing in over $£ 400$ million to the tourist industry. It will soon be the fastest expanding and most dynamic part of the tourist trade. A good example is medicine in that, as the practice of medicine becomes more complicated, specialization and subdivision become more widespread. There is a corresponding growth of professional societies and associations representing the various fields of medicine and, as more new information becomes available, they tend to meet more frequently both at national and international levels. The same trends apply to other professions especially scientists, economists and sociologists.

A young, active and brilliant scientist attended a large international conference in Sydney where he met an attractive colleague from Australasia. After 3 days' acquaintanceship they spent the last 2 nights 
of the conference in bed together and the following day he flew to Los Angeles, where he had previously spent a year as a postgraduate student. He met an old girl friend and during his one day stay they had sex together. He returned to London and was welcomed home by his new girl friend and on that night they had intercourse twice together. The following morning he noticed burning on micturition and by the afternoon he had a purulent urethral discharge which stained his underwear. When he attended the clinic the next day his symptoms were worse and he was diagnosed as having gonorrhoea and given treatment with penicillin. He chose to sit down in the clinic with the health visitor and write 2 letters, one to the girl in Sydney and one to the girl in Los Angeles, explaining that he had contracted gonorrhoea and that they might be infected and should obtain expert medical advice immediately. He went home and explained the situation to his new girl friend, who came to the clinic the following day with a contact slip given to him by the health visitor. She was found to have gonorrhoea at her second visit and treated. The girl in Los Angeles wrote to say that she had been given epidemiological treatment by her private physician, who had not even examined her, and he never heard again from the girl in Sydney.

These examples of case histories give some idea of the impact of travel on the spread of sexually transmitted diseases. The great mobility of large sections of the population and the ease of modern travel are resulting in infections crossing national and continental boundaries with great rapidity. It is now possible to fly twice round the world in the incubation period of gonorrhoea. No country, no state, no island that has an airport can be protected from sexually transmitted diseases brought in by travellers and tourists. Nor is there any satisfactory way of screening visitors. The most important steps that can be taken to try to establish some control over the incidence of the diseases are to raise the standards of clinical practice in the speciality everywhere, improve national and international contact tracing and provide better education for the public about the diseases.

The ordinary tourist, the business traveller and the conference delegate will wish to travel more often and further afield in future, despite the present fuel crisis. As populations increase, as incomes rise, as paid holidays lengthen and as the real cost of air travel becomes stabilized or starts to fall once more, the tourist industry will grow rapidly once again. We may now have an interval in growth and a pause in which to think about the problems of the spread of disease throughout the world and a chance to find some solutions to the many problems created by modern travel. The future of tourism represents a serious challenge to our ability to organize ourselves successfully and our response to it may well determine the patterns of infectious diseases throughout the world for the remainder of this century and beyond.

\section{References}

British Co-operative Clinical Group (1970) Gonorrhoeg study. British Journal of Venereal Diseases, 46, 62.

Caletri, G. (1974) In: Report of a Working Party on Venerea Diseases. Council of Europe, European Public Healt Committee, Strasbourg.

Guthe, T. (1974) In: Report of a Working Party on Venereal Diseases. Council of Europe, European Public Health Committee, Strasbourg.

SCHOFIELD, C.B.S. (1965) Venereal disease imported by mariners. British Journal of Venereal Diseases, 41, 51.

Siboulet, A. (1973) Les infections urogénitales 1961-1972. Report of the World Health Organization, Geneva.

Willcox, R.R. (1966) Immigration and venereal disease in Great Britain. British Journal of Venereal Diseases, 42, 225. Young, G. (1973) Tourism. Pelican Books, London. 